\title{
Prevalence of distal caries in mandibular second molars adjacent to impacted third molars: a retrospective study using panoramic radiography
}

\begin{abstract}
Introduction: Impacted teeth may be non-functional, abnormal or pathologic and the etiology of impaction depends on several factors. The aim of this study was to evaluate the correlation between the age and gender of the patient, side, eruption angulation and level of impaction of mandibular third molars (M3Ms) and the prevalence of distal caries lesions in mandibular second molars (M2Ms) at the same side eruption.
\end{abstract}

Methods: In this retrospective, panoramic radiographs acquired over three year's period were screened. Inclusion criterion was the presence of an erupted M2M and an impacted $\mathrm{M} 3 \mathrm{M}$ in the same quadrant. The radiographs were evaluated by two observers on the presence of M2M distal caries lesions. Shiller and Pell-Gregory classifications were used to assess the angulation and degree of impaction of the M3Ms, respectively. Chi-Square tests and a logistic regression model were used for data evaluation.

Results: 1104 M3M-M2M were evaluated. The prevalence of distal caries lesions on M2M was $38.7 \%(n=427)$. Gender, age, and side did not influence $(\mathrm{p}=0.120,0.496$, and 0.286 , respectively) the prevalence of caries lesions. The level and the angle of impaction were significantly relevant $(\mathrm{p}<0.001)$. Using $A$ as the reference for impaction level, M2Ms next to $\mathrm{B}$ - M3Ms presented less caries lesions (odds ratio of $0.574, \mathrm{p}=0.001$ ). Horizontal M3Ms seemed to present an increased risk of caries on the M2Ms $(\mathrm{p}<0.001)$.

Discussion: The caries prevalence seems to be significantly influenced by the positioning of the impaction. When deciding on the prophylactic removal of M3Ms, this issue should also be considered.
Volume 8 Issue 6 - 2017

\author{
Nur Altiparmak' Yener Oguz, ${ }^{2}$ Rubens Spin \\ Neto, ${ }^{3}$ Burak Bayram,' Ulkem Aydin ${ }^{4}$ \\ 'Department of Oral and Maxillofacial Surgery, Baskent \\ University, Turkey \\ ${ }^{2}$ Private Practice, Dubai \\ ${ }^{3}$ Private Practice, Turkey \\ ${ }^{4}$ Department of Dentomaxillofacial Radiology, Baskent \\ University, Turkey
}

Correspondence: Nur Altiparmak, Department of Oral and Maxillofacial Surgery, Faculty of Discipline, Baskent University, II. sok. No: 26, 06490 Bahcelievler,Turkey,

Email nuraltiparmak@hotmail.com

Received: October 26, 2017 | Published: November 2I, 2017

\section{Introduction}

Teeth may become impacted when they fail to erupt or develop into the proper functional location. Impacted teeth may therefore be non-functional, abnormal or pathologic., ${ }^{1,2}$ Mandibular third molars (M3Ms) exhibit high impaction rates, ranging from 9.5 to $50 \%{ }^{3,4}$ The etiology of M3M impaction depends on several factors, such as genetics, lack of space, retarded growth process, growth direction, eruption direction, and influence of external oblique line. ${ }^{5}$ Impacted M3Ms may cause pain, periodontal disease, pericoronitis, caries, tumor, angle fracture, dental crowding, and cyst formation..$^{6-11}$ The complications related to M3Ms have been long studied and reported in literature. However, many of the researches conducted are on the pathoses related to the tooth itself, and not to its surrounding anatomic structures. More recently, distal caries in the mandibular second molars (M2Ms) have attracted researchers and clinicians attention, but there are still not many studies on this topic. Among all complications related to impact M3Ms, distal caries of the M2M is one of the most common $(0.5-20 \%) .{ }^{12-15} \mathrm{~A}$ previous study reported that the prevalence of distal caries in M2Ms caused by third molars is up to $32 \% .{ }^{16}$ The aim of this study was to evaluate the correlation between the age and gender of the patient, side, eruption angulation and level of impaction of mandibular third molars and the prevalence of distal caries lesions in mandibular second molars.

\section{Method}

In this retrospective, cross-sectional study; digital panoramic radiographs that were made between the years 2009 and 2012 were evaluated. The radiographs of the patients aged between 20 to 30 years, who were admitted to Baskent University-Turkey were initially screened. The main inclusion criteria was the presence of an erupted mandibular second molar (M2M) and an impacted mandibular third molar (M3M) at the same quadrant. Patients which panoramic radiographs presenting distortion or low diagnostic quality (decided by subjective evaluation), and patients with restored M2Ms were excluded from the study in the initial evaluation. The radiographs were examined and evaluated by two trained oral and maxillofacial surgeons, separately. A 17-inch monitor (Dell, USA) was used for image evaluation, which was performed in a room with dimmed light. The angulation and impaction degree of the M3Ms, and the presence of distal caries lesions of M2Ms were assessed on the images. The observers were free to use the brightness, contrast, and magnification tools. The angulation of the M3M was assessed using the method previously described by Shiller WR, ${ }^{17}$ in which the angulation is determined by measuring the angle of the intersection made by the mandibular occlusal plane and the occlusal surface of the M3M. The angular measurements were made using the dedicated software (Mediadent, v.6.10.10.14F, Belgium). The method is illustrated in 
Figure 1. The angular classification used in the present study is based on a modified Shiller scale, which divides the angulation of M3M into six categories. Third molars with a negative angle (less than $0^{\circ}$ ) were considered as distoangular $(0)$, between $0-20^{\circ}$ as vertical (1), between $21-40^{\circ}$ as mesioangular $1(2), 41-60^{\circ}$ as mesioangular 2 (3), $61-80^{\circ}$ as mesioangular 3 (4), and angles greater than $80^{\circ}$ as horizontal (5). The level of impaction of the M3M was assessed using the method previously described by Pell-Gregory.18 According to this classification, tooth is defined as: A, when the highest portion of the impacted M3M is on level with or above the occlusal plane; B, when the highest portion of the impacted M3M is below the occlusal plane but above the cervical line of the M2M; or C, when the highest portion of the impacted M3M is below the cervical line of the M2M. These classifications are illustrated in Figure 2. In cases which the evaluations of the two investigators resulted in diverse classifications, were excluded from the study. When the investigators were not in agreement on the presence of M2M distal caries lesions, a second (consensus) evaluation was made, and if a consensus was not reached, the case was also excluded from the study. The final sample was composed of 1104 mandibular third molars, on 688 digital panoramic radiographs. The presence/absence of distal caries lesions on the M2M was selected as the dependent variable. Age (using 25 years as the cut point), gender, M3Ms angle, and M3Ms degree of impaction were defined as independent variables. Data was statistically evaluated using Chi-Square tests and a multinomial logistic regression model, by dedicated software (SPSS 12.0, SPSS Inc., Chicago-IL, USA). The study was approved by Baskent University Institutional Review Board Project No: D-KA14/03.

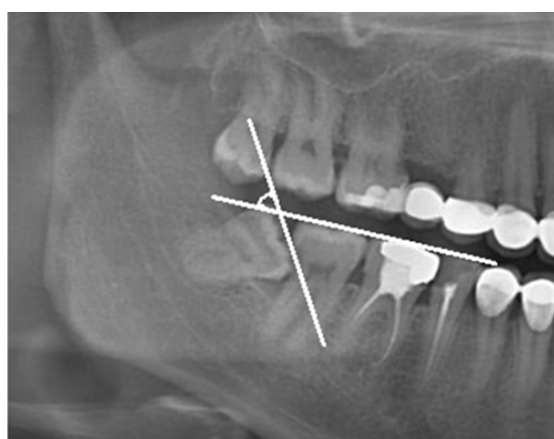

Figure I Shiller Classification, the angulation is determined by measurin the angle of the intersection made by the mandibular occlusal plane and the occlusal surface of the M3M.

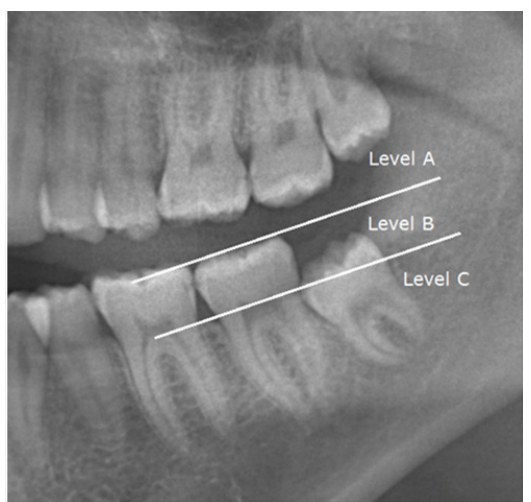

Figure 2 Pell-Gregory classification, tooth is defined as: $A$ : when the highest portion of the impacted M3M is on level with or above the occlusal plane; $B$ : when the highest portion of the impacted M3M is below the occlusal plane but above the cervical line of the M2M; C: when the highest portion of the impacted M3M is below the cervical line of the M2M.

\section{Results}

Post-hoc power analysis showed that the included sample was able to provide statistical power close to $90 \%$, with significance levels set to $5 \%$. In the total sample (688 patients), 448 (65.1\%) were female and $240(34.9 \%)$ were male. The mean age of the patients was 25.6 years, ranging from 20 to 30 years, as previously defined in the inclusion criteria. Among the $1104 \mathrm{M} 3 \mathrm{M}-\mathrm{M} 2 \mathrm{M}$ evaluated, the prevalence of distal caries lesions on M2M was $38.7 \%(n=427)$. Both gender and age did not have a significant impact on that prevalence ( $\mathrm{p}=0.120$ and 0.496 , respectively). These results are shown in Table 1. The side of the M3M had no influence on our results $(p=0.286)$, while the level and the angle of impaction played a significant role (in both cases, with a $\mathrm{p}<0.001$ ), when the prevalence of caries in the M2M was considered isolated. These results are shown in Table 2. Similar results were found when the data was evaluated based on a multinomial logistic regression model, which the level and the angle of impaction of the M3M being found as the relevant parameter interfering with the logistic regression results, as shown in Table 3. Using A as the impaction level reference, those M2M next to B-M3M presented less caries lesions (with a 0.574 (0.409-0.807) odds ratio) compared to the reference, with a significance of 0.001 ( $\mathrm{p}$-value). Using the category 0 of impaction angle as a reference, categories 2 , 4 , and 5 seemed to present an increased risk of caries lesions on the M2M, which the highest odds ratio $(3.508 ; 1.877-6.555)$ being found for category $5(\mathrm{p}<0.001)$. These results are shown in Table 4 .

Table I Distribution of caries lesions in M2M according to gender and age

\begin{tabular}{lllll}
\hline & $\begin{array}{l}\text { Total } \\
(\mathbf{n = 1} \text { I 04) }\end{array}$ & $\begin{array}{l}\text { Non-Caries } \\
(\mathbf{n = 6 7 7})\end{array}$ & $\begin{array}{l}\text { Caries } \\
(\mathbf{n}=427)\end{array}$ & Chi-Square (p) \\
Gender & & & \\
\hline Female & 717 & $452(63.0 \%)$ & $265(37.0 \%)$ & 0.12 \\
Male & 387 & $225(58.1 \%)$ & $162(41.9 \%)$ & \\
Age & & $331(62.5 \%)$ & $199(37.5 \%)$ & 0.496 \\
$20-25$ & 530 & $346(60.0 \%)$ & $228(40.0 \%)$ & \\
$26-30$ & 574 & &
\end{tabular}

Table 2 Distribution of caries lesions in the M2M according to impaction level, angle, and side

\begin{tabular}{|c|c|c|c|c|}
\hline Level & $\begin{array}{l}\text { Total } \\
(n=1 \text { I 04) }\end{array}$ & $\begin{array}{l}\text { Non-Caries } \\
(n=677)\end{array}$ & $\begin{array}{l}\text { Caries } \\
(n=427)\end{array}$ & Chi-Square (p) \\
\hline$A$ & 426 (38.6\%) & $293(43.3 \%)$ & \multicolumn{2}{|c|}{$133(3|| \%)<0.00 \mid}$. \\
\hline B & $419(37.9 \%)$ & $224(33.1 \%)$ & \multicolumn{2}{|l|}{195 (45.7\%) } \\
\hline C & $259(23.5 \%)$ & $160(23.6 \%)$ & \multicolumn{2}{|l|}{$99(23.2 \%)$} \\
\hline \multicolumn{5}{|c|}{ Angle } \\
\hline 0 & $150(13.6 \%)$ & $109(16.1 \%)$ & $4 \mathrm{I}(9.6 \%)$ & $<0.001$ \\
\hline I & $54 \mid(49.0 \%)$ & $366(54.1 \%)$ & \multicolumn{2}{|l|}{175 (4I.0\%) } \\
\hline 2 & 130 ( I I.8\%) & $60(8.8 \%)$ & \multicolumn{2}{|l|}{$70(16.4 \%)$} \\
\hline 3 & 155 (|4.1\%) & $90(13.3 \%)$ & \multicolumn{2}{|l|}{$65(15.2 \%)$} \\
\hline 4 & 45 (4.0\%) & 14 (2.1\%) & \multicolumn{2}{|l|}{$31(7.3 \%)$} \\
\hline 5 & $83(7.5 \%)$ & $38(5.6 \%)$ & \multicolumn{2}{|l|}{45 (10.5\%) } \\
\hline \multicolumn{5}{|l|}{ Side } \\
\hline Left & $562(50.9 \%)$ & $336(49.6 \%)$ & \multicolumn{2}{|c|}{$226(52.9 \%) 0.286$} \\
\hline Right & $542(49.1 \%)$ & $34 \mathrm{I}(50.4 \%)$ & \multicolumn{2}{|l|}{201 (47.1\%) } \\
\hline
\end{tabular}


Table 3 Likelihood ratio test for a multinomial logistic regression model, seeking for relevant parameters for regression, regarding the presence of caries in the second molar

\begin{tabular}{ll}
\hline Parameter & Chi-Square $(\mathbf{p})$ \\
\hline Gender & 0.19 \\
Age & 0.161 \\
Level & 0.003 \\
Angle & $<0.001$ \\
Side & 0.336
\end{tabular}

Table 4 Multinomial logistic regression model, presenting only the relevant parameters for regression, regarding the presence of caries lesions in the M2M. Odds ratio lower than I refer to a minor risk of caries lesions, while odds ratio larger than I refer to an augmented risk of caries lesions

\section{Significance (p) Odds Ratio Lower IC95\% Higher IC95\%}

\begin{tabular}{lllll}
\hline \multicolumn{2}{l}{ Level } & & & \\
$\mathrm{A}$ & Reference & & & \\
$\mathrm{B}$ & 0.001 & 0.574 & 0.409 & 0.807 \\
$\mathrm{C}$ & 0.288 & 0.809 & 0.547 & 1.196 \\
\multicolumn{1}{l}{ Angle } & & & & \\
0 & Reference & & & \\
$\mathrm{I}$ & 0.246 & 0.63 & 0.288 & 1.376 \\
2 & 0.02 & 1.943 & 1.111 & 3.399 \\
3 & 0.777 & 1.086 & 0.612 & 1.928 \\
4 & $<0.001$ & 2.716 & 1.618 & 4.559 \\
5 & $<0.001$ & 3.508 & 1.877 & 6.555 \\
\hline
\end{tabular}

\section{Discussion}

Several studies have been made on impacted M3Ms in developed countries, where millions of dollars are spent annually on the management of impacted third molars. In fact, the removal of impacted $\mathrm{M} 3 \mathrm{M}$ is regarded as the most common oral surgery performed. ${ }^{19-22}$ Preventive extraction has been recommended to eliminate unforeseen problems caused by third molars. Although there are several studies related to the indications for M3M extraction, there has been yet no consensus on guidelines for preventive removal of M3Ms. Two management options can be considered in the case of asymptomatic impacted third molars: prophylactic removal, with the aim of avoiding the morbidity associated with tooth extraction in elderly patients, and conservative management in which the teeth are not removed until they develop pathological manifestations. ${ }^{21}$ The probability of impacted M3M causing future pathologic changes may have been exaggerated. Many impacted or unerupted third molars may eventually erupt normally and many of them never cause clinically important problems. In addition, third molar removal is not a risk free surgery, and the complications following M3M removal surgery may be considerable. ${ }^{23-26}$ Therefore, prophylactic removal should only be carried out if there is good evidence of patient benefit. The proportion of prophylactic M3M removal surgery which is carried out in asymptomatic patients is difficult to estimate and depends on the definitions used. ${ }^{27}$ Many studies have been conducted on the complications that impacted M3M may cause, such as pericoronitis. However, few correlation studies were done between the distal caries on M2Ms and eruption status of M3Ms. ${ }^{13-15}$ Punwutikorn et al. ${ }^{28}$ stated that pain and pericoronitis were the most common problems and caries of the M2M was the second pathologic entity related with partially erupted M3Ms. The findings of Knuttson et al. ${ }^{29}$ were similar to that research. They have reported that the most frequently encountered pathologic entity was pericoronitis and the second was caries. Previous studies have shown that the incidence of M2M caries lesions is between $0.5-20 \% .12-15,34$ Van der Linden et al. ${ }^{16}$ reported the highest incidence of M2M caries and they have found 32\% distal caries lesions in their study. In the present study, the prevalence of distal caries lesions in M2Ms was $38.7 \%$, which is higher when compared with other studies, and may be due to racial, regional and/or socio-cultural differences. Differences between the diagnostic criteria of caries lesions can be another reason for the high prevalence of caries found in the present study. In vitro studies enable the researchers to validate caries by using histopathologic detection of caries as the golden standard, in contrast to clinical and radiographic studies. ${ }^{30}$ In order to overcome this drawback, two observers independently evaluated the radiographs, and in the case of disagreement, a second evaluation was made. If the two observers could not reach a consensus in this session, the case was discarded from the study. On the other hand, the preferred radiographic technique for caries diagnosis is bitewing radiography and incipient carious lesions may not be detected with panoramic radiographs. However, panoramic radiographs are usually the technique of choice for imaging the impacted M3M and the surrounding bone..$^{31-33}$ Hence, this retrospective study was also conducted on panoramic radiographs. Eruption of the third molars normally occurs between the ages of 17 and 21 years. ${ }^{35}$ Normally the age of M3M removal is between 25-28 years. Almendros-Marques et al. ${ }^{36}$ stated that most of the complications related with M3M impaction were recorded at patients between 16-30 years and prophylactic removal is beneficial under 25 to 30 years old. Punwitikorn et al. ${ }^{28}$ have reported that most of the patients in their study range from 1630 years, mostly between 21 to 25 years. Chang et al. ${ }^{15}$ stated that the delayed removal of the M3Ms increased the risk of caries lesions on the M2Ms. Our results show that, compared to other parameters, age is not a criteria that increases the prevalence of distal caries lesions in M2Ms, as the patients are between 20 to 30 years, with a mean age of 25.6. In our study, the prevalence of M3Ms with an impaction level of A in the carious M2M group was significantly higher than the other level groups. Polat et al ${ }^{37}$ reported that distal caries on M2Ms occur more frequently when the impaction level of the M3M is A rather than B or C. Chang et al. ${ }^{15}$ reported that the incidence of M3Ms with an impaction level A has more tendency to M2Ms caries lesion. The results of the present study are in agreement with the results of the mentioned ones. Chang et al. ${ }^{15}$ stated that the incidence of M3Ms with a mesial angulation between $40^{\circ}$ and $80^{\circ}$ in the carious M2Ms are relatively high when compared with noncarious group. Ozec et al. ${ }^{14}$ concluded that partially erupted M3Ms with angles between $30^{\circ}-90^{\circ}$ should be removed to prevent the risk of M2Ms caries. Mc. Ardle et al. ${ }^{13}$ concluded that distal cervical caries of the M2Ms are in the presence of mesio-angular M3Ms. In this retrospective radiographic study, dietary and nutritional patterns of the patient, smoking, medical conditions (such as diabetes), were not recorded. Nevertheless, within the limitations of this study, it can be suggested that mesio-angular or horizontally impacted M3Ms represent a risk for the development of distal caries lesions in M2Ms. We hypothesize that horizontal and 
impaction degree of A M3Ms can increase food packing and plaque retention on the distal surface of the M2Ms.

\section{Conclusion}

The prevalence of distal caries lesions in M2Ms was significantly higher when the highest portion of the impacted M3M is on level with or above the occlusal plane and M2M is next to horizontal-angulated $\mathrm{M} 3 \mathrm{M}$. The caries prevalence seems to be significantly influenced by the positioning of the impaction. When deciding on the prophylactic removal of M3Ms, this issue should also be considered.

\section{Funding}

None.

\section{Acknowledgments}

None.

\section{Conflicts of interest}

None.

\section{References}

1. Waite PD, Reynolds RR. Surgical management of impacted third molars. Semin Orthod. 1998;4(2):113-123.

2. Killy HC, Kay LW The impacted wisdom tooth. 3rd ed. Publishers Churchill Livingstone, UK. 1978; p. 18-19.

3. Hellman M. Some aspects of wisdom teeth and their impactions. Arch Clin Oral Path. 1938;2: 125.

4. Ricketts RM, Turley P, Chaconas S, et al. Third molar enucleation: diagnosis and technique. $J$ Calif Dent Assoc. 4(4): 52-57.

5. Svendsen H, Maertens JKM Etiology of third molar Impaction. Textbook and Color Atlas of Tooth Impactions. 1st ed. Munksgaard, Denmark. 1997. p. 223-227.

6. Eliasson S, Heimdahl A, Nordenram A. Pathological changes related to long-term impaction of third molars: A radiographic study. Int $J$ Oral Maxillofac Surg. 1989;18(4):210-212.

7. Lysell L, Rohlin M. A study of indications used for removal of the mandibular third molar. Int J Oral Maxillofac Surg. 1988; 17: 161-164.

8. Stanley HR, Alattar M, Collett WK, et al. Pathological sequelae of neglected impacted third molars. J Oral Pathol. 1988;17(3):113-117.

9. Stathopoulos P, Mezitis M, Kappatos C, et al. Cysts and tumors associated with impacted third molars: is prophylactic removal justified? $J$ Oral Maxillofac Surg. 2011;69(2):405-408.

10. Cankurtaran CZ, Branstetter BF, Chiosea SI, et al. Best cases from the AFIP: ameloblastoma and dentigerous cyst associated with impacted mandibular third molar tooth. Radiographics. 2010;30(5):1415-1420.

11. Güven O, Keskin A, Akal UK. The incidence of cysts and tumors around impacted third molars. Int J Oral Maxillofac Surg. 2000;29(2):131-135.

12. Al-Khateeb TH, Bataineh AB. Pathology associated with impacted mandibular third molars in a group of Jordanians. J Oral Maxillofac Surg. 2006;64(11):1598-1602.

13. McArdle LW, Renton TF. Distal cervical caries in the mandibular second molar: an indication for the prophylactic removal of the third molar? Br J Oral Maxillofac Surg. 2006;44(1):42-45.

14. Ozeç I, Hergüner Siso S, Taşdemir U, et al. Prevalence and factors affecting the formation of second molar distal caries in a Turkish population. Int $J$ Oral Maxillofac Surg. 2009;38(12):1279-1282.
15. Chang SW, Shin SY, Kum KY, et al. Correlation study between distal caries in the mandibular second molar and the eruption status of the mandibular third molar in the Korean population. Oral Surg Oral Med Oral Pathol Oral Radiol Endod. 2009;108(6):838-843.

16. Van der Linden W, Cleaton-Jones P, Lownie M. Diseases and lesions associated with third molars. Review of 1001 cases. Oral Surg Oral Med Oral Pathol Oral Radiol Endod. 1995;79(2):142-145.

17. Shiller WR. Positional changes in mesio-angular impacted mandibular third molars during a year. J Am Dent Assoc. 1979; 99(3): 460-464.

18. Pell GJ, Gregory GT. Impacted mandibular third molars: classification and modified technique for removal. Dent Digest. 1933; 39: 330-338.

19. Edwards MJ, Brickley MR, Goodey RD, et al. The cost, effectiveness and cost effectiveness of removal and retention of asymptomatic, disease free third molars. Br Dent J. 1999;187(7):380-384.

20. Edwards DJ, Horton J, Shepherd JP, et al. Impact of third molar removal on demands for postoperative care and job disruption: does anaesthetic choice make a difference? Ann R Coll Surg Engl. 1999;81(2):119-123.

21. Flick WG . Third molar controversy: framing the controversy as a public health policy issue. J Oral Maxillofac Surg. 1999;57(4): 438-444.

22. Ogden GR, Bissias E, Ruta DA, et al. Quality of life following third molar removal:a patient versus professional perspective. $\mathrm{Br}$ Dent $\mathrm{J}$. 1998;185(8):407-410.

23. Shepherd JP, Brickley M. Surgical removal of third molars. BMJ. 1994;309(6955):620-621.

24. Stephens RG, Kogon, SL, Reid JA The unerupted or impacted third molar-a critical appraisal of its pathologic potential. J Can Dent Assoc. 1989;55: 201-207.

25. Ahlqwist M, Gröndahl HG. Prevalence of impacted teeth and associated pathology in middle-aged and older Swedish women. Community Dent Oral Epidemiol. 1991;19(2):116-119.

26. Mercier P, Precious D. Risks and benefits of removal of impacted third molars. A critical review of the literature. Int J Oral Maxillofac Surg. 1992;21(1):17-27.

27. Almendros-Marqués N, Alaejos-Algarra E, Quinteros-Borgarello M, et al. Factors influencing the prophylactic removal of asymptomatic impacted lower third molars. Int J Oral Maxillofac Surg. 2008;37(1):29-35.

28. Punwutikorn J, Waikakul A, Ochareon P. Symptoms of unerupted mandibular third molars. Oral Surg Oral Med Oral Pathol Oral Radiol Endod. 1999;87(3):305-310.

29. Knutsson K, Brehmer B, Lysell L, et al. Pathoses associated with mandibular third molars subjected to removal. Oral Surg Oral Med Oral Pathol Oral Radiol Endod. 1996;82(1):10-17.

30. Kamburoglu K, Kolsuz E, Murat S, et al. Proximal caries detection accuracy using intraoral bitewing radiography, extraoral bitewing radiography and panoramic radiography. Dentomaxillofac Radiol. 2012;41(6):450-459.

31. Flint DJ, Paunovich E, Moore WS, et al. A diagnostic comparison of panoramic and intraoral radiographs. Oral Surg Oral Med Oral Pathol Oral Radiol Endod. 1998;85(6):731-735.

32. Lurie AG. Panoramic imaging. In: White SC \& Phaorah M. Oral Radiology: Principles and interpretation. 3rd ed. Mosby, USA. 2008.

33. Wenzel A Dental caries. In: White SC \& Paul W Goaz. Oral Radiology: Principles and interpretation. 3rd ed. Mosby, USA, 2008; 720 p.

34. Mejare I, Kallestal C, Stenlund H, et al. Caries development from 11 to 22 years of age: a prospective radiographic study. Prevalence and distribution. Caries Res. 1998;32(1):10-16. 
35. Fuller JL, Denehy GE. Concise dental anatomy and morphology. 3rd ed. Year Book Medical Publishers Inc, USA. 1999; p. 1-225

36. Almendros-Marques N, Berini-Aytes L, Gay-Escoda C. Influence of lower third molar position on the incidence of preoperative complications. Oral Surg Oral Med Oral Pathol Oral Radiol Endod. 2006;102(6):725-732.
37. Polat HB, Ozan F, Kara I, et al. Prevalence of commonly found pathoses associated with mandibular impacted third molars based on panoramic radiographs in Turkish population. Oral Surg Oral Med Oral Pathol Oral Radiol Endod. 2008;105:e41-e47. 